\title{
PENGARUH KEPEMIMPINAN, PROGRAM SERTIFIKASI, DAN PENGEMBANGAN KEPROFESIONALAN TERHADAP KINERJA GURU PADA SMA NEGERI DI KABUPATEN BANYUWANGI AKHLAKUL KARIMAH, SE
}

\author{
Program StudiMagister Manajemen, Fakultas Ekonomi, Universitas Jember
}

\begin{abstract}
Education is a place that aims to establish and educate a qualified Human Resources, have expertise and can build the character of the nation that is able to compete in the field of science and technology that fear of God Almighty and virtuous noble character. This study aims to determine the effect of leadership, certification programs and professional development on teacher performance in high schools in Banyuwangi.

The population is the number of teachers 531 Civil Servants that has been certified in 17 state high schools throughout Banyuwangi. Sampling in this study using the proportional random sampling with 105 teachers. The model used in this study is a model of causality or influence relationships. To test the hypothesis that will be proposed in this study the analysis techniques to be used is SEM or Structural Equation Modeling program operated through AMOS.

The study shows that leadership and certification programs affect to improve the performance of teachers through professional development. Where leadership affect professional development of teachers with a coefficient of 0.43 . The certification program is a variable that affects the professional development of teachers with a coefficient of 0.48 . Impact of school leadership on teacher performance with a coefficient of 0.23 . The certification program has an influence on performance improvement of teachers with a coefficient of 0.22 . Professional development that affects the performance of teachers with a coefficient of 0.12. And leadership and certification programs to improve the performance of teachers through professional development with a coefficient of 0.33 .
\end{abstract}

Keywords: leadership, certification programs, professional development, teacher performance

\section{PENDAHULUAN}

Banyak kalangan yang berpendapat bahwa problematika yang dihadapi bangsa Indonesia merupakan masalah yang krusial dan multidiminsional, yang disebabkan oleh kualitas SDM (sumber daya manusia). Rendahnya SDM baik secara akademis maupun nonakademis menyebabkan minimnya komponen bangsa untuk berpartisipasi memberikan kontribusi dalam konteks pembangunan bangsa, dimana keadaan tersebut bisa diatasi dengan peningkatan kualitas SDM secara berkesinambungan. Menilai kualitas suatu bangsa dapat dilihat dari mutu pendidikan bangsa tersebut.

Sekolah adalah lembaga formal yang diselenggarakan dalam rangka mencapai pendidikan nasional. Dalam usaha meningkatkan kualitas pendidikan, guru merupakan komponen sumber daya manusia yang harus dibina dan dikembangkan secara terus menerus, karena guru memegang peranan yang sangat penting dalam peningkatan mutu pendidikan. Bardawi dan Mohammad Arifin (2012:43), menjelaskan bahwa faktor internal kinerja guru adalah faktor yang datang dari dalam diri guru yang dapat mempengaruhi kinerjanya. Faktor eksternal kinerja guru adalah faktor yang datang dari luar guru yang dapat mempengaruhi kinerjanya, diantaranya adalah ; (1) kepemimpinan; (2) gaji; (3) lingkungan kerja fisik ; (4) sarana prasarana. Kepemimpinan kepala sekolah akan diterima oleh guru-guru apabila kepemimpinan yang diterapkan sangat cocok dan disukai oleh guru-gurunya, sehingga guru akan memiliki kecenderungan untuk meningkatkan kinerjanya. Kita tahu bahwa peningkatan 
kualitas mengajar dan kompetensi guru juga merupakan salah satu tanggung jawab pemerintah, maka dalam rangka meningkatkan mutu pendidikan nasional melalui peningkatan komponen mutu guru, maka pemerintah meluncurkan program sertifikasi guru. Martinis Yamin (2013:2),

sertifikasi guru adalah proses pemberian sertifikat pendidik kepada guru untuk bukti formal sebagai pengakuan yang diberikan kepada guru sebagai tenaga profesional. Dengan menyandang predikat guru profesional, maka pekerjaan guru adalah pekerjaan profesi yang dilaksanakan secara profesional, guru akan mendapatkan gaji dan tunjangan fungsional sebagaimana yang telah diatur dalam Keputusan Presiden Republik Indonesia nomor 3 tahun 2003. Yang semuanya bertujuan untuk menghasilkan guru yang profesional yang memiliki kompetensi dalam merencanakan, melaksanakan, mengevaluasi pembelajaran, menindak lanjuti hasil penilaian dengan melakukan pembimbingan, pelatihan peserta didik, serta guru mampu melakukan penelitian dan pengembangan keprofesionalan secara berkelanjutan.

Tujuan yang ingin dicapai dari penelitian ini adalah:

a. Menganalisis pengaruh kepemimpinan terhadap pengembangan keprofesionalan guru pada SMA Negeri di Kabupaten Banyuwangi.

b. Menganalisis pengaruh program sertifikasi terhadap pengembangan keprofesionalan guru pada SMA Negeri di Kabupaten Banyuwangi.

c. Menganalisis pengaruh kepemimpinan terhadap kinerja guru pada SMA Negeri di Kabupaten Banyuwangi.

d. Menganalisis pengaruh program sertifikasi terhadap kinerja guru pada SMA Negeri di Kabupaten Banyuwangi.

e. Menganalisis pengaruh pengembangan keprofesionalan guru terhadap kinerja guru pada SMA Negeri di Kabupaten Banyuwangi

\section{HIPOTESA}

Berdasarkan rumusan masalah dan tujuan penelitian, maka hipotesis penelitian yang diajukan adalah sebagai berikut :

H1 : Kepemimpinan berpengaruh positif terhadap pengembangan keprofesionalan guru SMA Negeri di Kabupaten Banyuwangi.

H2 : Program Sertifikasi berpengaruh positif terhadap pengembangan keprofesionalan guru SMA Negeri di Kabupaten Banyuwangi.

H3 : Kepemimpinan berpengaruh positif terhadap kinerja guru SMA Negeri di Kabupaten Banyuwangi.

H4: Program sertifikasi berpengaruh positif terhadap kinerja guru SMA Negeri di Kabupaten Banyuwangi.

H5: Pengembangan keprofesionalan guru berpengaruh positif terhadap kinerja guru SMA Negeri di Kabupaten Banyuwangi 


\section{KERANGKA PEMIKIRAN}

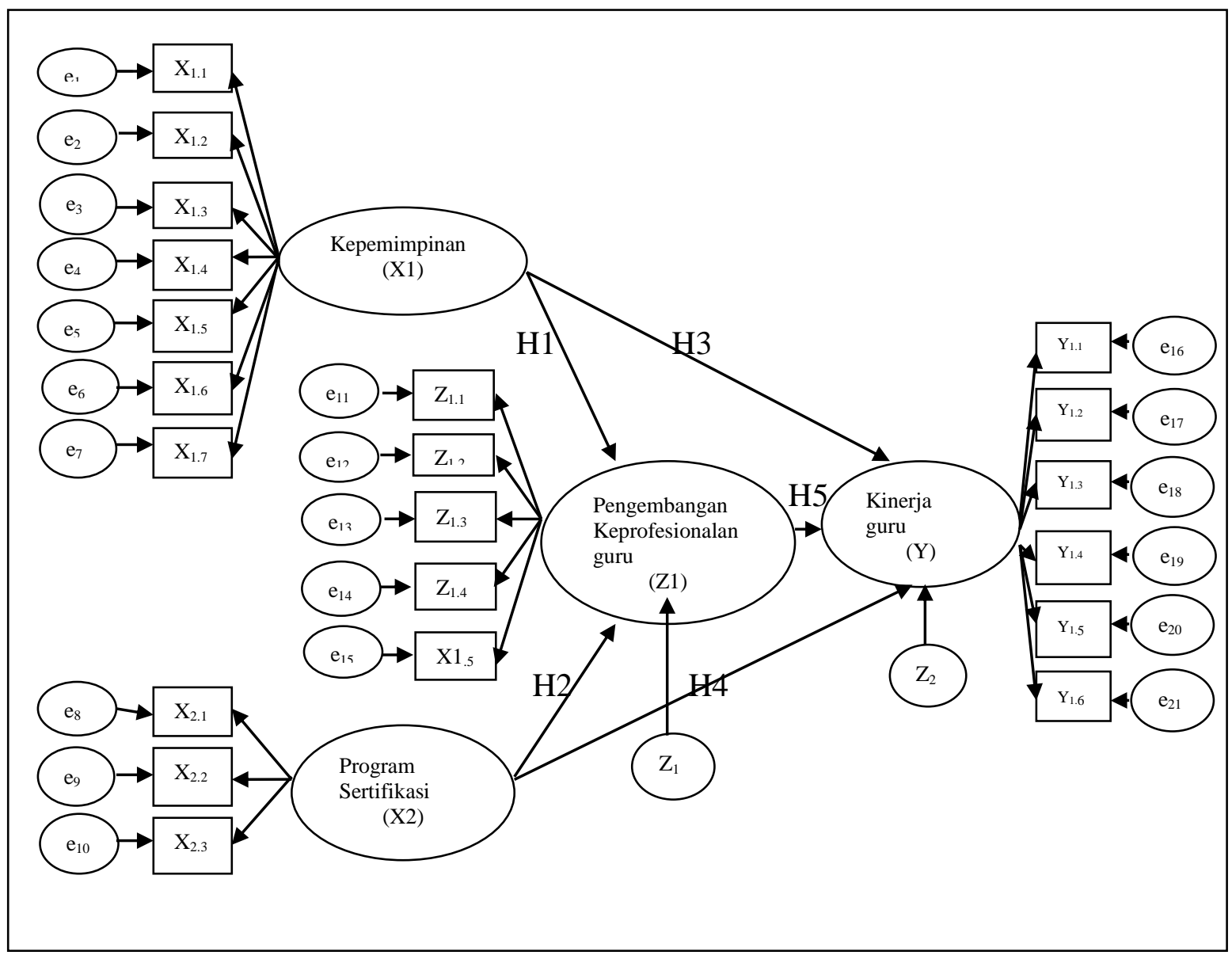

\section{METODE PENELITIAN}

\section{Kerangka Konseptual Penelitian}

Penelitian ini adalah termasuk dalam jenis penelitian explanatory dan Penelitian confirmatory, yang digunakan untuk menguji teori berdasarkan hipotesis dan mengemukakan pengaruh Kepemimpinan, Program Sertifikasi, dan Pengembangan Keprofesionalan Terhadap Kinerja Guru Pada SMA Negeri di Kabupaten Banyuwangi. Dalam penelitian ini populasi yang digunakan adalah sejumlah 531 guru Pegawai Negeri Sipil. Pengambilan sampel dengan dasar perhitungan rumus 5 hingga $10 \mathrm{x}$ parameter yang diestimasi. Estimated parameter dalam penelitian ini sejumlah 21 indikator, maka jumlah sampel yang diambil minimal 105 - 210 sampel, maka yang diambil sebagai sampel 105 guru karena menurut standar minimal sampelm yang ideal dengan teknik analisis SEM menurut Ferdinand (2006) bahwa untuk sampel yang sesuai adalah 100-200. Untuk menganalisis data digunakan The Structural Equation Modeling (SEM) dari paket software statistik AMOS dalam model dan pengkajian hipotesis. Model persamaan structural, Structural Equation Model (SEM) adalah sekumpulan teknikteknik statistical yang memungkinkan pengujian sebuah rangkaian hubungan relative "rumit" secara simultan (Ferdinand, 2006).

Penelitian ini bertujuan untuk menguji pengaruh kepemimpinan(X1) dan program sertifikasi (X2) terhadap kinerja guru (Y). Hubungan keduanya melalui pengembangan keprofesionalan (Z1). Artinyap kepemimpinan dan program sertifikasi meningkatkan pengembangan keprofesionalan terlebih dahulu baru kemudian meningkatkan kinerja guru. Jadi, selengkapnya variabel dalam penelitian ini, adalah sebagai berikut ;

Variabel Eksogen : Kepemimpinan (X1) dan program sertifikasi (X2) 
Variabel Endogen : Kinerja guru (Y)

Variabel Intervening : Pengembangan keprofesionalan (Z)

Definsi operasional ini dibuat untuk menyamakan persepsi antara peneliti dengan pembaca, atau pengguna hasil penelitian (Hasan, 2002:151). Adapun definisi operasional dari masing-masing variabel penelitian dapat diuraikan sebagai berikut :

a. Kepemimpinan
1) Edukator (pendidik)
2) Manajer
3) Administrator
4) Supervisor
5) Leader
6) Inovator
7) Motivator

b. Program Sertifikasi $\left(\mathrm{X}_{2}\right)$ Adapun indikatornya adalah sebagai berikut:

1) Kualifikasi akademik

2) Standart kompetensi

3) Sertifikat Sertifikasi

c. Pengembangan Keprofesionalan Guru ( $\left.\mathrm{Z}_{1}\right)$. Dimana pengembangan guru berdasarkan kebutuhan institusi adalah penting, namun hal yang lebih penting adalah berdasar kebutuhan individu guru untuk menjalani proses profesionalisasi. Adapun indikatornyaa adalah sebagai berikut :

1) Idividual Guided Staff Development (pengembangan guru yang dipacu secara individual)

2) Observation / Assessment (observasi atau penilaian)

3) Involvement in a development / Improvement Process (keterlibatan dalam suatu proses pengembangan/peningkatan)

4) Training (pelatihan)

5) Inquiry (pemeriksaan)

d. Kinerja guru (Y).Kinerja guru merupakan keberhasilan guru dalam melaksanakan tugas pendidikan sesuai dengan tanggung jawab dan wewenangnya berdasarkan standar kinerja yang telah ditetapkan selama periode tertentu dalam kerangka mencapai tujuan pendidikan. Adapun indikatornya adalah sebagai berikut :

1) Kemampuan yang dimiliki guru

2) Prakarsa/inisiataif

3) Ketepatan waktu

4) Kualitas hasil kerja yang harus dimilki oleh seorang guru

5) Komunikasi

6) Beban mengajar guru

Skala pengukuran variabel dalam penelitian ini menggunakan skala perhitungan Likert yaitu metode yang mengukur sikap dengan menyatakan setuju dan tidak setuju terhadap subjek, objek atau kejadian tertentu (Sugiyono, 2006:55). Metode ini dikembangkan oleh Rennis Likert dan dikenal dengan skala Likert.

\section{HASIL PENELITIAN}

Setelah semua asumsi dapat dipenuhi, selanjutnya akan dilakukanpengujian hipotesis, dimana pengujian hipotesis ini adalah dengan menganalisis sebagai berikut :

a. Nilai Critical Ratio (CR) dan nilai Probability (P) Hasil olah data dari penelitian, dibandingkan dengan batasan statistik yang disyaratkan, yaitu diatas 1,96 untuk nilai CR dan dibawah 0,05 untuk nilai P (probabilitas), menurut Ferdinand (2006:256). Apabila 
hasil olah data menunjukkan nilai yang memenuhi syarat tersebut, maka hipotesis penelitian yang diajukan dapat diterima.

Kesimpulan Hipotesis

\begin{tabular}{|c|c|c|c|}
\hline & Hipotesis & Nilai CR dan P & Hasil Uji \\
\hline $\mathrm{H} 1$ & $\begin{array}{l}\text { Kepemimpinan berpengaruh positif } \\
\text { terhadap pengembangan keprofesional } \\
\text { pada guru SMA Negeri di Kabupaten } \\
\text { Banyuwangi }\end{array}$ & $\begin{array}{l}\mathrm{CR}=8,981 \\
\mathrm{P}=0,000\end{array}$ & Diterima \\
\hline $\mathrm{H} 2$ & $\begin{array}{l}\text { Program sertifikasi berpengaruh positif } \\
\text { terhadap pengembangan keprofesionalan } \\
\text { guru SMA Negeri di Kabupaten } \\
\text { Banyuwangi }\end{array}$ & $\begin{array}{l}C R=6,574 \\
P=0,005\end{array}$ & Diterima \\
\hline $\mathrm{H} 3$ & $\begin{array}{l}\text { Kepemimpinan berpengaruh positif } \\
\text { terhadap kinerja guru SMA Negeri di } \\
\text { Kabupaten Banyuwangi. }\end{array}$ & $\begin{array}{l}\mathrm{CR}=8,773 \\
\mathrm{P}=0,043\end{array}$ & Diterima \\
\hline $\mathrm{H} 4$ & $\begin{array}{l}\text { Program sertifikasi berpengaruh } \\
\text { signifikan terhadap kinerja guru SMA } \\
\text { Negeri di Kabupaten Banyuwangi }\end{array}$ & $\begin{array}{l}\mathrm{CR}=7,880 \\
\mathrm{P}=0,042\end{array}$ & Diterima \\
\hline H5 & $\begin{array}{l}\text { Pengembangan keprofesionalan } \\
\text { berpengaruh positif terhadap kinerja guru } \\
\text { SMA Negeri di Kabupaten Banyuwangi. }\end{array}$ & $\begin{array}{l}\mathrm{CR}=8,548 \\
\mathrm{P}=0,030\end{array}$ & Diterima \\
\hline
\end{tabular}

Dari hasil pengujian diperoleh bahwa semua nilai CR berada di atas 1,96 atau dengan,probabilitas yang lebih kecil dari 0,05. Dengan demikian semua Hipotesis diterima.

b. Analisis kausalitas untuk menganalisis kekuatan pengaruh antar konstruk baik pengaruh yang langsung, tidak langsung, dan pengaruh totalnya. Efek langsung (direct effect) tidak lain adalah koefisien dari semua garis koefisien dengan anak panah satu ujung. Efek tidak langsung (indirect effect) adalah efek yang muncul melalui sebuah variabel antara. Efek total (total effect) adalah efek dari berbagai hubungan (Ferdinand, 2006).

\section{Pengaruh Langsung dan Tidak Langsung Dan Pengaruh Total}

\begin{tabular}{lccc}
\hline Keterangan & $\begin{array}{c}\text { Pengaruh } \\
\text { Langsung ke } \\
\text { Kineja } \\
(\mathbf{a})\end{array}$ & $\begin{array}{c}\text { Pengaruh Tidak } \\
\text { Langsung ke } \\
\text { Kinerja } \\
(\mathbf{b})\end{array}$ & $\begin{array}{c}\text { Total ke } \\
\text { Kinerja } \\
(\mathbf{a})+(\mathbf{b})\end{array}$ \\
\hline Kepemimpinan & 0,24 & $0,43 \times 0,25=0,11$ & 0,35 \\
Program Sertifikasi & 0,22 & $0,48 \times 0,25=0,12$ & 0,33
\end{tabular}

Berdasarkan hasil perhitungan pengaruh langsung maupun pengaruh tidak langsung kepemimpinan dan program sertifikasi terhadap kinerja guru, yang menunjukkan satu komparasi yang mengarah pada lebih tingginya pengaruh langsung dari kepemimpinan daripada program sertifikasi terhadap kinerja, dimana pengaruh kepemimpinan terhadap kinerja secara langsung diperoleh sebesar 0,24 sedangkan secara tidak langsung diperoleh 
sebesar 0,11. Begitu pula dengan program sertifikasi yang menunjukkan bahwa pengaruh langsung lebih tinggi,dimana diperoleh pengaruh program sertifikasi terhadap kinerja guru secara langsung diperoleh sebesar 0,22 sedangkan secara tidak langsung diperoleh sebesar 0,12 .

\section{Pengaruh Kepemimpinan Terhadap Pengembangan Keprofesionalan}

Parameter estimasi untuk pengujian kepemimpinan terhadap pengembangan keprofesionalan menunjukkan nilai CR sebesar 8,981 dan dengan probabilitas sebesar 0,000. Kedua nilai tersebut diperoleh memenuhi syarat untuk penerimaan $\mathrm{H} 1$ yaitu nilai CR yang lebih besar dari 1,96 dan probabilitas yang lebih kecil dari 0,05. Hasil dari kedua nilai ini memberikan informasi bahwa pengaruh kepemimpinan terhadap pengembangan keprofesionalan pada SMA Negeri di Kabupaten Banyuwangi dapat diterima, karena memenuhi syarat diatas 1,96 untuk CR dan dibawah 0,05 untuk nilai $\mathrm{P}$, dengan demikian dapat dikatakan bahwa hipotesis 1 penelitian ini dapat diterima.

\section{Pengaruh Program Sertifikasi Terhadap Pengembangan Keprofesionalan}

Parameter estimasi untuk pengujian pengaruh program sertifikasi terhadap pengembangan keprofesionalan menunjukkan nilai CR sebesar 6,574 dan dengan probabilitas sebesar 0,005 . Kedua nilai tersebut diperoleh memenuhi syarat untuk penerimaan $\mathrm{H} 2$ yaitu probabilitas yang lebih kecil dari 0,05 . Hasil dari kedua nilai ini memberikan informasi bahwa pengaruh program sertifikasi terhadap pengembangan keprofesionalan pada SMA Negeri di Kabupaten Banyuwangi dapat diterima, karena memenuhi syarat diatas 1,96 untuk CR dan dibawah 0,05 untuk nilai $\mathrm{P}$, dengan demikian dapat dikatakan bahwa hipotesis 2 penelitian ini dapat diterima.

\section{Pengaruh Kepemimpinan Terhadap Kinerja Guru}

Parameter estimasi untuk pengujian pengaruh kepemimpinan terhadap kinerja guru menunjukkan nilai CR sebesar 8,773 dan dengan probabilitas sebesar 0,043. Kedua nilai tersebut diperoleh memenuhi syarat untuk penerimaan $\mathrm{H} 3$ yaitu nilai CR yang lebih besar dari 1,96 dan probabilitas yang lebih kecil dari 0,05. Hasil dari kedua nilai ini memberikan informasi bahwa pengaruh kepemimpinan terhadap kinerja guru pada SMA Negeri di Kabupaten Banyuwangi dapat diterima, karena memenuhi syarat diatas 1,96 untuk CR dan dibawah 0,05 untuk nilai $P$, dengan demikian dapat dikatakan bahwa hipotesis 3 penelitian ini dapat diterima. Berdasarkan hasil pengamatan pada analisis pengaruh langsung maupun pengaruh tidak langsung menunjukkan bahwa pengaruh kepemimpinan terhadap kinerja secara langsung diperoleh sebesar 0,24 sedangkan secara tidak langsung diperoleh sebesar 0,11. Artinya kepemimpinan kepala sekolah akan meningkatkan kinerja guru secara langsung meski tanpa didukung adanya pengembangan keprofesionalan. Berarti guru SMA Negeri di Kabupaten Banyuwangi, memang telah profesional dalam profesinya sebagai guru.

\section{Pengaruh Program Sertifikasi Terhadap Kinerja Guru}

Parameter estimasi untuk pengujian pengaruh program sertifikasi terhadap kinerja guru menunjukkan nilai CR sebesar 7,880 dan dengan probabilitas sebesar 0,042. Kedua nilai tersebut diperoleh memenuhi syarat untuk penerimaan $\mathrm{H} 4$ yaitu nilai CR yang lebih besar dari 2,58 dan probabilitas yang lebih kecil dari 0,05. Hasil dari kedua nilai ini memberikan informasi bahwa pengaruh program sertifikasi terhadap kinerja guru pada SMA Negeri di Kabupaten Banyuwangi dapat diterima, karena memenuhi syarat diatas 1,96 untuk CR dan dibawah 0,05 untuk nilai $P$, dengan demikian dapat dikatakan bahwa hipotesis 4 penelitian ini dapat diterima. Berdasarkan hasil pengamatan pada analisis pengaruh langsung maupun pengaruh tidak langsung menunjukkan bahwa program sertifikasi yang menunjukkan bahwa 
pengaruh langsung lebih tinggi,dimana diperoleh pengaruh program sertifikasi terhadap kinerja guru secara langsung diperoleh sebesar 0,22 sedangkan secara tidak langsung diperoleh sebesar 0,12. artinya program sertifikasi akan mempengaruhi kinerja guru lebih tinggi meski tidak dimediasi oleh pengembangan keprofesionalan. Yang berarti guru di SMA Negeri di Kabupaten Banyuwangi, telah bertanggung jawab terhadap predikat guru yang profesional dan memegang sertifikat pendidik, dengan ditunjukkan pengaruh yang baik terhadap kinerjanya, walupun tanpa pengembangan keprofesionalan.

\section{Pengaruh Pengembangan Keprofesionalan Terhadap Kinerja Guru}

Parameter estimasi untuk pengujian pengaruh pengembangan keprofesionalan terhadap kinerja guru menunjukkan nilai CR sebesar 8,548 dan dengan probabilitas sebesar 0,030. Kedua nilai tersebut diperoleh memenuhi syarat untuk penerimaan H5 yaitu nilai CR yang lebih besar dari 1,96 dan probabilitas yang lebih kecil dari 0,05. Hasil dari kedua nilai ini memberikan informasi bahwa pengaruh pengembangan keprofesionalan terhadap kinerja guru pada SMA Negeri di Kabupaten Banyuwangi dapat diterima, karena memenuhi syarat diatas 1,96 untuk $\mathrm{CR}$ dan dibawah 0,05 untuk nilai $\mathrm{P}$, dengan demikian dapat dikatakan bahwa hipotesis 5 penelitian ini dapat diterima.

\section{KESIMPULAN}

Semakin tinggi dan kuat kepemimpinan membentuk karakter pimpinan (atasan) maka semakin tinggi keinginan guru untuk melakukan pengembangan keprofesionalan. Guru yang telah menerima sertifikasi membuat semakin tinggi keinginan guru untuk melakukan pengembangan keprofesionalan. Berarti dapat disimpulkan bahwa faktor-faktor kepemimpinan kepala sekolah berpengaruh positif terhadap kinerja guru. Berarti menunjukkna program sertifikasi mampu meningkatkan kinrja guru pada SMA Negeri di Kabupaten Banyuwangi.

Maka dapat disimpulakan bahwa kepemimpinan dan program sertifikasi akan lebih meningkatkan kinerja guru SMA Negeri di Kabupaten Banyuwangi, jika melalui pengembangan keprofesionalan. Hasil dari temuan penelitian disarakan sesuai dengan prioritas yang dapat diberikan sebagai masukan bagi pihak pimpinan. Berikut ini diuraikan beberapa saran alternatif yang bersifat strategis guna meningkatkan kinerja guru pada SMA Negeri di Kabupaten Banyuwangi, maka yang harus senantiasa ditingkatkan, yaitu:

1) Pada kepemimpinan kepala sekolah perlu lebih ditingkatan implimentasi kepemimpinan, terutama dalam dalam hal inovator, yaitu kepala sekolah diharapkan agar lebih melakukan peningkatan dan mampu menemukan, atau merumuskan berbagai pembaharuan dan menjadi pencetus ide-ide kemajuan dalam pendidikan dan pengajaran untuk diterapkan disekolah.

2) Dalam pengembangan keprofesionaln pada guru SMA Negeri Banyuwangi perlu ditingkatkan pada kegiatan Training, dimana guru diharapkan agar lebih melakukan peningkatan dan mampu menerapkan teknikteknik dan prilaku-prilaku yang pantas untuk ditiru dalam kelas.

3) Hasil-hasil dalam penelitian ini dan keterbatasanketerbatasan yang ditemukan agar dapat dijadikan sumber ide dan masukan bagi pengembangan penelitian ini dimasa yang akan datang, maka perluasan yang disarankan dari penelitian ini antara lain adalah: menambah variabel independen yang mempengaruhi pengembangan keprofesionlan dalam meningkatkan kinerja guru. Variabel yang disarankan seperti dukungan organanisasi sekolah, lingkungan dan lain sebagainya. 


\section{DAFTAR PUSTAKA}

Aas Hasanah. 2005. Pengaruh Prilaku Kepemimpinan Kepala Sekolah Terhadap Kinerja Guru di SLTPN Kota Bandung” Sekolah Pasca Sarjana UPI: Jurnal Tesisi

Arikunto, Suharsimi. 2003. Prosedur Penelitian, Jakarta: Bina Aksara .2005. Prosedur Penelitian Suatu Pendekatan Praktek. Jakarta: PT Rineka Citra .2003. Manajemen Penelitian. Jakarta: Rineka Cipta

Aritonang, Keke T. "Kompensasi Kerja, Disiplin Kerja Guru dan Kinerja Guru SMP Kristen BPK Penabur Jakarta. "Dalam Jurnal Pendidikan Penabur No.04/Th.IV/Juli 2005.

Akmad, S. 2008, Peran Kepala Sekolah dalam Meningkatkan Kompetensi Guru. Jakarta: Rineke Cipta.

Bafadal, Ibrahim. 2009. Seri Manajemen Peningkatan Mutu Pendidikan Berbasis Sekolah Peningkatan Profesionalisme Guru Sekolah Dasar dalam Kerangka Manajemen Peningkatan Mutu Berbasis Sekolah. Jakarta : Bumi Aksara

Bardawi \& Mohammad Arifin. 2012. Kinerja Guru Profesional. Instrumen Pembinaan, Peningkatan \& Penilaian. Jogjakarta: Ar-Ruzz, Media.

Castetter, W.B. 1981. The Personnel Function in Educational Administration. Pennsylvania: Macmillan.

Denim, Sudarmawan. 2010. Profesionalisasi dan Etika Profesi Guru. Bandung: CV Alfabeta.

Duncan, W. Jack. 1981. 2nd Edition, Organizational Behavior.Boston, Houghton Mifflin Comp.

Fakry Gaffar, Mohammad 1996, Tantangan dan Arah Baru Bagi Manajemen LPTK. Bandung: IKIP Bandung.

Ferdinand, Augusty, 2006, Structural Equation Modeling Dalam Penelitian Manajemen, Badan Penerbit Universitas Diponegoro.

Ghozali, Imam. 2008. Structural Equation Modeling Metode Alternatif dengan Partial Least Square-PLS, Edisi Kedua, Semarang: Badan Penerbit Universitas Diponogoro.

Hadi, Sutrisno, 1993, Metodologi Research, Jilid I, Andi Offset, Yogyakarta.

Hair, J.F.,Jr.,R.E. Anderson, R.L., Tatham \& W.C. Black, (1995), Multivariate Data Analysis With Readings, Englewood Cliffs, NJ: Prentice Hall. 
Hasibunan, Malayu .1999. Organisasi. Jakarta: Bumi Aksara

Hasibuan. M.S.P .2000.Manajemen Sumber-Daya Manusia. Jakarta: Bumi Aksara

Hersey, Paul and Kenneth H. Blanchard. 1977. Management, Organizational Behavior: Utilizing Human resources. Third Edition, Prentice Hall Inc., Englewood Cliffs, New Jersey.

Hengky Latan. 2013, Model Persamaan Sruktural, Teori dan Implementasi AMOS 21.0, Penerbit Alfabeta

Indriantoro, Nur \& Supomo, Bambang, 2002, Metodologi Penelitiaan Bisnis untuk Akuntansi dan Manajemen, Edisi 1, BPFE, Yogyakarta.

Jalal, F. 2005. Kebijakan Pendidikan dalam Profesionalisasi Pendidik dan Tenaga Kependidikan dalam Upaya Meningkatkan Kualitas Pendidikan. Bandung : FIP UPI

2007 “Peningkatan Mutu Pendidikan dan Tenaga Kependidikan”. Dalam bahan Semiloka Sertifikasi Dosen Perguruan Tinggi Agama Islam. Jakarta, 27 Februari

Janawi. 2012. Kompetensi Guru.Citra Guru Profesional. Bandung: Alfabeta

KOMPAS, 20 Nopember 2004

Kunandar, 2008. Guru Profesional Implementasi Kurikulum Tingkat Satuan Pendidikan (KTSP) Dan Suksess Dalam Sertifikasi Guru. Jakarta: PT Raja Grafindo Persada

Martinis Yamin. 2013. Sertifikasi Profesi Keguruan di Indonesia. Dilengkapi UU No. 14 Tahun 2005 tentang Guru dan Dosen. Ciputat : Refrensi (GP Press Group)

Mas'ud, Fuad, 2004, Survai Diagnosis Organisasional Konsep dan Aplikasi, Badan Penerbit,BP-UNDIP, Semarang.

Mitchel, T. R. Dan Larson. 1987. People an Organization: An Introduction to Organizational Behavior. Singapore: Mc Graw Hill Inc

Mulyasa. E. 2006. Menjadi guru Profesional menciptakan Pembelajaran Kreatif dan Menyenangkan. Bandung: Alfabeta.

Nazir, M. 2003. Metode Penelitian. Jakarta: Ghalia Indonesia.

Riduwan. 2007. Metode \& Teknik Menyususn Tesis. Bandung: CV Alfabeta

Riduwan. 2008. Skala Pengukuran Variabel-variabel Penelitian. Bandung: Alfabeta.

Robbins, Stephen P, 2006, Perilaku Organisasi, Edisi kesepuluh, PT Indeks Jakarta. 
Sanusi, A., dkk. 1990. Studi Pengembangan Model Pendidikan Profesional Tenaga Kependidikan : Laporan Kemajuan, Bandung : PPS IKIP Bandung

Sartono Wirodikromo. 2004. Matematika, Jakarta : Penerbit Erlangga

Sugiyono. 2006, Metode Penelitian Bisnis, Alfabeta, Bandung.

Supriadi, Dedi. 1999. Mengangkat Citra dan Martabat Guru. Yogyakarta : Adicipta Karya Nusa.

Surya, M. 2005. Mencermati Kebijakan Pendidikan dalam Mewujudkan Kemandirian Guru. Makalh Simposium Nasional Pendidikan tentang Rekonstruksi Profesi guru Kerangka Reformasi Pendidikan di Unmuh Malang.

Tabachnick, B. G., \& Fidell, L.S. 1996. Using Multivariate Statistics. (3rd ed). New York: HarperCollins College Publishers.

Udin Saefudin Saud. 2008. Pengembangan Profesi Guru. Bandung : Penerbit Alfabeta.

Usman, M.U. 2002. Menjadi Guru Profesional, Bandung: PT Remaja Rosdakarya

Undang-undang Republik Indonesia Nomor 20 Tahun 2003. Tentang Sistem Pendidikan Nasional. Diknas. Jakarta

Undang-Unadang Republik Indonesi Nomor 14 tahun 2005. Tentang Guru dan Dosen. Departemen Pendidikan Nasional Republik Indonesia. Jakarta

Usman, M.U. 2002. Menjadi Guru Profesional, Bandung: PT remaja Rosdakarya

Wahjosumidjo. 1999. Kepemimpinan Kepala Sekolah. Tinjauan Teoritik dan Permasalahannya. Jakarta: PT Rajagrafindo Persada.

Yuniarsih, Jutju \& Suwarno. 2009. Manajemen Sumber Daya Manusia: Teori, Aplikasi, dan Isu Penelitian.Bandung : Alfabeta. 
